THĭLANCET,] Mí. MUMMERY: A NEW OPERATION FOR PROLAPSE OF THE RECTUM. [MARCH 5, 1910.641

The results may be briefly summarised in the following table:-

\begin{tabular}{c|c|c|c|c|c|c}
\hline $\begin{array}{c}\text { No. of } \\
\text { lobes. }\end{array}$ & $\begin{array}{c}\text { No. } \\
\text { of } \\
\text { cases. }\end{array}$ & $\begin{array}{c}\text { Tempera- } \\
\text { ture varia- } \\
\text { tions. }\end{array}$ & $\begin{array}{c}\text { De- } \\
\text { pressed. }\end{array}$ & Raised. & $\begin{array}{c}\text { Other } \\
\text { changes. }\end{array}$ & $\begin{array}{c}\text { Amenor- } \\
\text { rhoea- }\end{array}$ \\
\hline & & $\%$ & $\%$ & $\%$ & $\%$ & $\%$ \\
1 & 284 & $68=23.9$ & $51=75.0$ & $14=20.5$ & $3=4.4$ & $34=11.9$ \\
2 & 160 & $30=18 \cdot 7$ & $12=40.0$ & $16=53.3$ & $2=6.6$ & $38=23.7$ \\
3 or more. & 56 & $7=12.5$ & $1=14.2$ & $4=57 \cdot 1$ & $2=28.4$ & $35=62.5$ \\
\hline
\end{tabular}

The accounts given in the text-books on the influence of menstruation on the temperature in healthy women are not entirely concordant. Lewers ${ }^{2}$ says the temperature is a little raised, about half a degree for some days before the flow, similarly falling again during and after it. Galabin, ${ }^{3}$ quoting Stephenson, says: "The curve of temperature is above the mean for about half the month, rising to about half a degree above the mean line; it crosses and falls below that line about or shortly before the onset of menstruation and sinks to a similar depth below it for about a similar interval." Hart and Barbour ${ }^{4}$ state that during the few days before the flow the temperature is slightly raised; J. C. Edgar ${ }^{\overline{5}}$ says the temperature is slightly elevated often by $1^{\circ} \mathrm{F}$. at the onset; whilst Webster ${ }^{6}$ says the temperature rises half a degree above the average before the period, falls during the flow, and goes down to half a degree below the average immediately after the period. Dudley ${ }^{7}$ says that there is a slight elevation of temperature at the onset. The most explicit account that I have been able to find is that of Dr. A. E. Giles, ${ }^{8}$ who states that "the temperature begins to rise about the middle of the inter-menstrual period, attaining its maximum two days before menstruation. There is a sudden drop on the day before the flow begins, with a second slighter drop towards the end of the period. It then rises sligbtly for the first week after the cessation of menstruation, and there is a third fall at the beginning of the intermenstrual period. The total variation only amounts to half a degree Fahrenheit." He also finds that " the pulse curve corresponds fairly closely with that of the temperature." Giles's results are in general accord with those of Jacobi ${ }^{9}$ and Reinl. ${ }^{10}$

It will be seen that the changes associated with pulmonary tuberculosis are, as might have been expected a priori, progressively more marked in proportion to the severity and extent of the disease. Thus in early cases the changes most frequently found are a depression in the temperature, somewhat more marked but otherwise similar to that occurring in the healthy woman, except that the temperature falls on the first day and not on the day preceding the flow; and, further, the progressive and preliminary rise in the intermenstrual period appears to occur but rarely, being present in only three of my cases. In cases with two lobes affected a definite rise occurs in more than half of them, whilst in cases with three or more lobes affected a simple depression occurs in only 14.2 per cent. of the cases, a rise in 57 per cent. I was unable to trace any definite variation of pulse-rate and respiration with these changes of temperature. In like manner the amenorrhoea that is so well recognised as a sequel of this disease is found to increase progressively in proportion to the extent and severity of the disease. In early cases it occurred in 11.9 per cent.. in the two-lobed in 23.7 per cent., whilst in the severe and advanced it occurred in as many as 62.5 per cent. The only references of the effect of menstruation on the temperature in pulmonary tuberculosis that $I$ have been able to find in the literature on this disease are by Dr. F. W.

2 Lewers: Diseases of Women, London, 1903, p. 49

4 Hart and Barbour: Manual of Gynacology, Edinburgh, 1904, p. 83. 3 J. C. Edgar : Practice of Obstetrics, London, 1907, p. 21. 7 Dudley: Principles and Practice of Gyn:cology, London, 1908, p. 23 .

8 Giles: The Cyclical or Wave Theory of Menstruation with Observathons on the Variations in Pulse and Temperature in Relation to Menstruation, 1897, Obstetrical Tramsactions, vol

9 Jacobi : Question of Rest for Women during Menstruation, 1877 New York

10 Reinl: Die Wellenbewegung der Lebensprocesse des Weibes, Volkmann's Sammlung, No. 243 .
Burton-Fanning ${ }^{11}$ who states as follows : "I find that in about half my female patients a characteristic rise of temperature occurs during the week that precedes the onset of menstruation; the average increase of temperature amounted in my cases to 0.50 and lasted for an average period of six days ending on the day before menstruation or extending over the first or second day of the flow"; and Dr. F. M. Pottinger 12 who states that, "It is not uncommon in females suffering from tuberculosis to have a rise in temperature associated with the menstrual period. It usually comes on a few days before the flow, but may not appear until it is established. In early cases this often amounts to only a fraction of a degree or a degree, but in advanced cases I have frequently seen a maximum of $103^{\circ}$ or $104^{\circ}$." The fact that the temperature appears to rise definitely in the more advanced and febrile cases would seem to indicate that the rest in these cases should be more rigidly enforced at the periods than at other times, and in any case it would be wise to postpone drawing inferences from the temperature chart in a case first seen during menstruation as to the nature and type of the lesion until the period is over, and the influence of menstruation upon the temperature can be eliminated.

West Norwood, S.E.

\section{A NEW OPERATION FOR PROLAPSE OF THE RECTUM.}

By J. P. LOCKhart MUMineRY, M.B., B.C. CantaB., F.R.C.S. FNG.

SENIOR ASSISTANT SURGEON TO ST. MARK'S HOSPITIAI FOR DISEASES OF THE RECTUM, CITY-ROAD, E.C., AND TO THE QUEEN'S HOSPITAL FOR CHILDREN, HACKNEY-ROAD, E.

PROLAPSE of the rectum in adults is a condition which, as a rule, is difficult to cure, and the large number of different operations which have been advocated for the treatment of this condition are sufficient evidence of the difficulty that is often experienced in curing such cases. I am, of course, excluding those cases in which a short prolapse occurs as a complication of severe and old-standing piles, where a ring of mucous membrane comes down with the piles, as these cases can be efliciently treated by a modified Whitehead's operation.

The operations for prolapse of the rectum in adults may be divided into two classes-those which aim at suspending the bowel from above, which includes all the different forms of colopexy, and those which aim at fixing the rectum itself into the hollow of the sacrum and to the pelvic fascia. These include all the different forms of proctopexy. The latter type of operation is, except in cases of prolapse of the third degree, the better, as it aims at restoring the natural supports of the rectum, and also it does not necessitate opening the peritoneal cavity.

Our object in performing any form of proctopexy is to anchor the rectum by adhesions to the sacrum and.surround. ing pelvic fascia. It is obvious that the more extensive and firm these adhesions are the better will be the result. Stitches, however carefully placed, cannot be permanently depended upon to hold up the rectum, and, further, it is quite impossible to stitch the rectum into the hollow of the sacrum. Even if the stitches are carried right round the sacrum, as in Tuttle's operations, this object is not attained, as the sacrum is hollow from side to side as well as from above downwards, and consequently the stitches cannot draw the post-rectal wall against the sacrum, as they remain stretched across the hollow like a bow-string.

The usual method of performing proctopexy is to stitch the posterior rectal wall to the tissues in front and on each side of the coccyx. The stitches, however, cannot permanently anchor the rectum, as they cut their way through the tissues and become loose in a very short time, and the ultimate result, in those cases where the operation succeeds, is due to the adhesions formed between the parts during the time the stitches hold.

The following operation is both simple and effectual as it so anchors the rectum as to render any possibility of the post-rectal wall prolapsing impossible. The preliminary

11 Burton-Fanning: The Open-air Treatment of Pulmonary Tuberculosis, London, 1909 , p. 36.

12 Pottinger: Pulmonary Tuberculosis, London, 1908, p. 57. 
treatment consists of getting patients' bowels well cleared out previous to the operation so that they may be left confined for some time afterwards. If at the time of the operation the prolapse is down it should be entirely reduced and the bowel thoroughly washed out with lysol solutionone drachm to the pint. A small plug of gauze should be passed into the bowel to prevent any leakage during the operation. The whole of the perineum and buttocks are then carefully asepticised and a transverse incision about two inches long is made about half way between the tip of the coccyx and the posterior margin of the anus. This incision should divide the attachment of the external sphincter to the coccyx and should be carried down until the posterior rectal space is opened. With the gloved finger this space should be freely opened up. The height to which the posterior rectal space should be separated depends upon the length of the prolapse, but in any case it should be well up into the hollow of the sacrum. The space should also be opened up slightly to each side of the bowel. Next a long strip of sterilised gauze should be lightly packed into the space thus made in the hollow of the sacrum and behind the rectum. The end of the gauze is left protruding from the wound, which must be left open. A lot of gauze must not be pushed in, but only just sufficient to prevent the rectum and the tissues on the front of the sacrum from healing together by primary

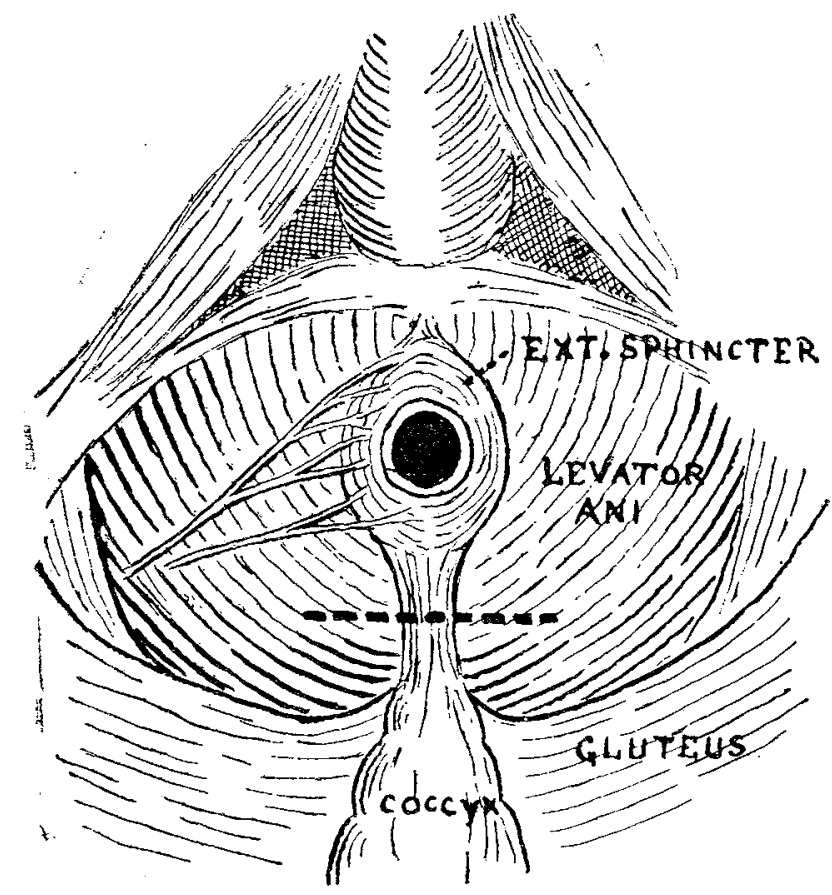

Diagram showing the muscles of the perineal and anal region. The transverse dotted line shows the position of the incision.

union. The external wound is carefully dressed, a piece of gauze being placed in the anus to prevent the dressings from becoming soiled. If the anus is very patulous some form of plastic operation may be performed at the same time to narrow the opening.

After the operation the patient must be kept lying flat in bed, and not allowed to sit up for any purpose. He should be given a very light and easily digested diet so as to enable the bowels to be kept from acting for some days. The gauze is removed on the third day and the wound then re-packed lightly each day, the wound and the space behind the rectum being allowed to close slowly by granulation, less and less gauze being introduced at each dressing. The bowels are opened by oil enemata on about the sixth or seventh day with the patient in the recumbent position, care being taken to prevent the prolapse from coming down. The wound heals up in about three weeks, but the patient should not be allowed to sit up for a full month after the operation.

After the wound has healed, if a finger is passed into the bowel, it will be found that the whole posterior wall of the rectum is firmly attached to the hollow of the sacrum by the fibrous tissue formed during the healing of the posterior wound. The posterior rectal wall is in this way much more effectually anchored than is possible by any stitching, and, moreover, is attached in the hollow of the sacrum where it cannot be stitched.

The division of the attachment of the external sphincter to the tip of the coccyx is an advantage, as in consequence of its division the anus is displaced slightly further forward, and this, combined with the posterior fixation, considerably increases the angle formed by the terminal portion of the rectal canal, and so tends to prevent further prolapse.

This operation has the advantage of great simplicity, while at the same time it affords a more effectual means of anchoring the posterior rectal wall than any operation depending on stitching can possibly do. The only risk of the operation is sepsis, which might be serious owing to the cellular spaces opened up, but with proper antiseptic technique this should be negligible, and after granulation has commenced, which will be after the first two or three days, no serious sepsis can occur, even should the wound become infected.

I have performed this operation four times with complete success, and appended are brief notes of three cases:-

CASE 1.-A woman, aged 42 years. Prolapse of second degree for three years. Bowel came down when the patient walked and caused great misery. About five inches of bowel prolapsed. The anus was return of the prolapse after the operation, and when last heard of was quite well.

CASE 2.-A man, aged 38 years. Severe prolapse of the rectum for over a year. The slightest strain caused the bowel to come down, and the patient suffered great inconvenience. About five inches of bowel protruded through the anus on straining. The anus was very patulous. Operation in 1904. When the patient began to walk after the wound had healed there was a slight prolapse of the anterior rectal wall, about one inch coming through the anus. This was treated by ligature at a second operation. Result, cured.

CASE 3.-A woman, aged 57 years. Prolapse for 14 years. Five months ago was operated on, Whitehead's operation being performed. This, the patient said, did no good, and the prolapse had been worse since. On examination the upper part of the rectum prolapsed through the anus,
Operation, 1907: Posterior wall of rectum anchored by producing adhesions to sacrum and some loose mucous membrane on anterio wall just within anus ligatured. Result, cured.

In each case about 5 inches of the bowel came down previous to operation. One patient, in whom the anus was very patulous, had a small prolapse of the anterior rectal wall when he began to get about again consisting of about an inch of the mucous membrane on the anterior rectal wall just within the sphincters. This portion of the mucous membrane was removed by ligature at a second operation, in the same way as in treating piles, and he then had no further trouble.

The advantages claimed for this operation are: (1) it securely and permanently fixes the whole posterior rectal wall into the hollow of the sacrum; (2) it is simple, and does not involve any serious risk; (3) it does not involve the cutting of any nerves or important structures; and (4) it restores the bowel to as near the normal condition as is possible.

Cavendish-place, W

Worthing and Defective School Children.The Worthing education committee on Feb. 22nd adopted its scheme for the treatment of defects revealed by the medical inspection of school children. The committee has been fortunate in having the advice of a medical practitioner as a member of the education authority. Mr. H. J. M. MilbankSmith voiced the feelings of the medical profession at Worthing when he said that the profession held strongly that work given by the education authority should not be undertaken by local charities or by private benevolence, but should be paid for by the authority. It is upon these lines that the education committee has finally approved of its scheme, and care has been taken not to cause inconvenience to any section of the community. Precautions will be taken to ensure that only those children shall be treated whose parents are found unable to pay for medical advice. The cost of ointments, lotions and dressings, \&c., is estimated at $£ 5$ per annum. For the treatment of defective eyesight it is proposed to appoint a special ophthalmic surgeon, and it is estimated that from 200 to 300 cases every year will be treated at a cost of 20 guineas per 100 cases. Parents are to pay for the cost of glasses, wholly or partially, and the cost to the education authority for the supply of glasses is estimated at $£ 20$ per annum. For tonsils and adenoids hospital tickets are to be given, the estimated cost for $100 \mathrm{such}$ cases being £21 per annum. 